\title{
O CRIME PASSIONAL NA PERSPECTIVA DE INFRATORES PRESOS: UM ESTUDO QUALITATIVO
}

\author{
Rosilene Almeida Santiago* \\ Maria Thereza Ávila Dantas Coelho\#
}

\begin{abstract}
RESUMO. O objetivo desta pesquisa foi apreender aspectos emocionais ligados ao crime passional, à vivência carcerária dos infratores presos por este delito e seus efeitos. A análise qualitativa dos prontuários e de entrevistas realizadas em duas penitenciárias de Salvador/BA deu-se a partir de categorias apreendidas nas narrativas. Verificou-se que os criminosos, ao se envolverem num relacionamento amoroso e se depararem com um rival ou uma situação de traição, ficam mobilizados pelos sentimentos de ciúme, amor e ódio, e por dúvidas que lhes causam um profundo sofrimento e os impelem ao crime. Percebendo-se, assim, numa situação sem saída, eles transgridem a lei, golpeando as suas vítimas e provocando lesões corporais, violência psicológica e homicídio. Tal ato é seguido por um processo de condenação judicial e de vivência carcerária marcado pelo sofrimento e pela estigmatização, que os fazem arrepender-se do delito cometido e desejar retomar o projeto de vida que foi interrompido.
\end{abstract}

Palavras-chave: Crime passional; aspectos emocionais; vivência carcerária.

\section{PASSIONAL CRIME IN THE PERSPECTIVE OF PRISONERS: A QUALITATIVE STUDY}

\begin{abstract}
This research aimed to apprehend emotional aspects of the passional crime, the experience of life in the prison and their effects. The qualitative analysis of handbooks and the interviews was carried through in two prisons of Salvador/BA. It occurred from categories apprehended in the narratives. It was verified that the criminals, if involved in a loving relationship and coming across with a rival or a situation of treason, are mobilized for the feelings of jealousy, love and hatred and for doubts that cause them a deep suffering and impels them to the crime. In a situation without exit, they transgress the law hitting and provoking body injuries, psychological violence and homicide. This act is followed by a judicial condemnation and by the experience of imprisonment, marked by suffering and stigmatization, which results in the feeling of regret and desire of going back to their project of life that was interrupted.
\end{abstract}

Key words: Passional crime; emotional aspects; experience of imprisonment.

\section{CRIMEN PASIONAL EN LA PERSPECTIVA DE LOS PRISIONEROS}

RESUMEN. El objetivo de esta investigación fue aprehender aspectos emocionales del crimen pasional, de la experiencia en la prisión y sus efectos. El análisis cualitativo de los prontuarios y entrevistas realizada en dos prisiones de Salvador/BA sucedió a través de las categorías aprehendidas en las narrativas. Fue verificado que los pasionales, si envueltos en una relación amorosa y si confrontados con un rival o una situación de traición, permanecen perturbados por sensaciones de los celos, del amor y del odio y por las dudas que causan un sufrimiento profundo y el crimen. En una situación sin salida, ellos traspasan la Ley y provocan lesiones del cuerpo, violencia psicológica y homicidio. Este acto es seguido por una condenación judicial y por una experiencia en la prisión, marcadas por sufrimiento y estigmatización, que los hace arrepentirse y desear reasumir el proyecto de vida interrumpido.

Palabras-clave: Crimen pasional; aspectos emocionales; experiencia en la prisión.

* Graduada em Psicologia.

\# Graduada em Psicologia, Mestre e Doutora em Saúde Coletiva pela UFBA. Professora Adjunta da Universidade Federal da Bahia e membro do Colégio de Psicanálise da Bahia. 
Apesar de o crime passional ser um tema relevante na atualidade, em Salvador/BA não existem pesquisas que o explorem. Nessa direção, buscamos desenvolver um estudo que investigasse os aspectos emocionais ligados a essa forma de violência, o processo de vivência carcerária dos infratores presos por este tipo de delito e os seus efeitos sobre tais indivíduos.

Cotidianamente em nossa sociedade verificamos que diversas modalidades de violência estremecem a população, com inúmeros crimes praticados no lar, na rua ou nas organizações. Esses delitos, que atingem todas as classes sociais, também se originam delas. A violência é propiciada por uma cultura que historicamente tolera excessos, tornando os relacionamentos normalmente violentos (Marcondes Filho, 2001). Ela tem raízes profundas nas relações de poder baseadas no gênero, na sexualidade, na autoidentidade e nas instituições sociais. A violência de gênero é um abuso de poder que fragiliza as relações entre homens e mulheres e que se fundamenta em uma sociedade patriarcal e machista, ainda que, atualmente, a organização familiar não seja responsabilidade exclusiva do homem (Osório, 2002). O pretenso direito do homem de dominar a mulher é, ademais, um fenômeno universal (Chollet, 2005a). A Organização Mundial de Saúde (OMS) relata que quase metade das mulheres assassinadas no mundo são mortas pelo marido ou namorado, seja ele o atual ou o anterior (Aquino, 2006). A estatística do Ministério do Interior Francês, por exemplo, informa que, na França, três mulheres são mortas pelo companheiro a cada quinze dias.

Derivado do latim passionalis, de passio (paixão), juridicamente o crime passional é aquele que se comete por paixão (Beraldo, 2004). Trata-se de um crime hediondo, cuja pena prevista é de 12 a 30 anos de reclusão. Constitui crime de motivo torpe (art.121, parágrafo $2^{\circ}$, do Código Penal) e é qualificado se o acusado, sentindo-se desprezado pela amada, resolve vingar-se, matando-a (Eluf, 2003). Não é, porém, a vingança, por si só, o motivo do delito. O crime passional, antes, era perdoado com base nos direitos superiores do homem sobre a mulher. O matador da mulher era visto com complacência, compaixão, e alguns eram absolvidos ao serem julgados pelo tribunal do júri, com base nesses direitos superiores. Quando os homens descobrem a traição por parte da companheira, transformam-se em juízes e executores.

Segundo Eluf (2003), o medo do ridículo é a mola do crime. Ela ressalta que o homicídio passional é classificado como um gravíssimo delito e afirma que não existe crime cometido por amor, mas sim por ódio, acrescentando que foi a Escola Positivista que exaltou o delinquente por amor. A cultura machista, ainda vigente em muitos estratos sociais, também contribui para a justificativa de matar em nome do amor. Por muito tempo, as leis propiciaram a interpretação do crime passional como defesa da honra ou legítima defesa.

\section{MÉTODO}

Este é um estudo qualitativo, por trabalhar com o universo dos significados, ações, relações, motivos, aspirações, crenças, valores e atitudes do ser humano (Minayo, 2004). Essas questões correspondem a um campo mais profundo das relações, processos e fenômenos não perceptíveis e não captáveis em equações, médias e estatísticas, que não podem ser reduzidos à operacionalização de variáveis. $\mathrm{O}$ método de pesquisa escolhido, além de operacionalmente possível, mostrou-se apropriado ao objeto desta investigação.

Nessa direção, este estudo, que inicialmente recebeu aprovação do Comitê de Ética em Pesquisa da Universidade Salvador, foi desenvolvido em duas unidades prisionais de Salvador-BA, mediante a autorização dos diretores das instituições, após esclarecimento verbal dos objetivos do estudo, dos procedimentos necessários à coleta dos dados e do sigilo quanto aos nomes dos internos e da instituição. $\mathrm{Na}$ instituição A, para a identificação dos crimes passionais, primeiramente foram selecionados, dentre os diversos tipos de delito relativos aos períodos de janeiro de 2005 a março de 2007, 85 crimes por homicídio ou tentativa de homicídio, e nove crimes por lesões corporais. $\mathrm{Na}$ instituição $\mathrm{B}$ foram solicitados de um funcionário os prontuários relativos a homicídios, tentativas de homicídio ou lesões corporais, totalizando 41 prontuários. Das duas instituições, foram somados 117 prontuários referentes a homicídios e tentativas de homicídio e nove prontuários referentes a lesões corporais. Os critérios utilizados para caracterizar o crime como passional foram que o delito cometido envolvesse um relacionamento amoroso, ciúme e traição real ou imaginária. A análise desses prontuários resultou na identificação de 22 criminosos passionais. Desse universo, dois recusaram-se a participar da pesquisa, um estava internado na época, seis já tinham sido liberados da instituição prisional e treze internos foram entrevistados. Os dados dos prontuários pertinentes a este estudo foram transcritos manualmente, dentro da própria instituição. 
No início das entrevistas, os internos foram informados verbalmente sobre os objetivos do estudo, de que as informações coletadas seriam utilizadas para fins de pesquisa e seus nomes e o da instituição seriam mantidos sob sigilo para garantir o anonimato. Quem consentisse responderia a uma série de perguntas, mas poderia interromper a entrevista no momento em que o desejasse, ou responder apenas às perguntas que quisesse, sendo assegurado que a sua escolha não causaria qualquer prejuízo à sua pessoa. Após aceitação verbal, foi-lhes apresentado para leitura e assinatura um Termo de Consentimento Livre e Esclarecido com esse mesmo conteúdo. Alguns o assinaram com caneta e outros, ainda não alfabetizados, com as impressões digitais do polegar.

Assim, foram realizadas treze entrevistas semiestruturadas, compostas de onze perguntas ligadas aos dados sociodemográficos e jurídicos, tais como naturalidade, idade, escolaridade, estado civil, profissão, antecedentes criminais, delito cometido, tempo total e de cumprimento da pena, acrescidas de 38 questões abertas sobre o relacionamento afetivo com a vítima, como ocorreu o crime, emoções experienciadas antes, durante e após o delito, reflexões sobre o ocorrido, vivência carcerária e projeto de vida. A formulação de tais questões se deu com base na discussão sobre esse tipo de violência, efetuada por autores citados neste artigo. Cada entrevista foi realizada num tempo médio de 60 minutos e registrada por escrito, considerando-se que a utilização de um gravador num ambiente prisional poderia ter um efeito de inibição durante a coleta de informações. Os dados das entrevistas, juntamente com os dos prontuários, foram descritos de forma ética e sigilosa no que diz respeito à exposição de alguns detalhes do crime. Posteriormente foram agrupados, categorizados e articulados de acordo com os objetivos da pesquisa, em consonância com a análise categorial proposta por Bardin (1977) e com o referencial da Teoria dos sistemas de signos, significados e práticas, desenvolvida por pesquisadores das Universidades de McGill e Montreal, no Canadá.

De acordo com Bardin (1977), a técnica de categorização é uma operação de classificação de elementos constitutivos de um conjunto, por diferenciação e reagrupamento por analogia. Ela é alcançada por meio da seleção de partes semelhantes do conteúdo, as quais são recortadas e agrupadas nas categorias criadas. Destarte, as categorias são rubricas ou classes que reúnem um grupo de elementos sob um título genérico, em razão dos caracteres comuns apresentados por estes elementos. Supõe-se que esse processo de decomposição e reorganização do conteúdo desempenhe uma função na indicação de correspondências entre o que é analisado e a realidade subjacente e revele aspectos invisíveis ao nível dos dados brutos.

Segundo a referida teoria, além dos significados sociais, econômicos, políticos, históricos e culturais coletivamente compartilhados, é importante considerar os significados singulares de cada sujeito, o que enriquece $o$ trabalho de interpretação. $O$ processo de análise dos dados baseia-se em alguns pressupostos da semiótica contemporânea de Peirce, Humberto Eco, Roland Barthes e Julia Kristeva, tais como o de que a relação entre o signo e a realidade é indireta e mediatizada pela linguagem e pela ideia de que existe uma pluralidade de significados relacionados ao contexto e ao processo sócio-histórico-cultural de produção de sentidos (Bibeau \& Corin, 1995). De acordo com essa perspectiva teórico-metodológica, a interpretação dos dados deve ocorrer em dois níveis. No primeiro nível, os significados apresentados pelos entrevistados devem ser apreendidos sem ser reelaborados; no segundo nível, devem ser estabelecidas relações entre estes significados e a literatura científica sobre o tema.

Esta pesquisa seguiu nessas direções. Inicialmente, a partir dos elementos afins identificados nas entrevistas e prontuários, foram criadas categorias, nas quais foi agrupado o material selecionado dos dados coletados. Posteriormente, no primeiro nível de interpretação, foram apreendidos os aspectos emocionais ligados ao crime passional, à vivência carcerária e seus efeitos, tais como eles foram explicitados pelos entrevistados. No segundo nível, por seu turno, questões foram problematizadas pelos pesquisadores de acordo com as relações estabelecidas entre as concepções dos presos e o quadro científico da pesquisa.

\section{RESULTADOS E DISCUSSÃO}

As categorias analíticas construídas a partir dos dados coletados por esta pesquisa foram: Amor e ódio; Rivalidade e ciúme; Intolerância à traição; Planejamento versus impulsividade; Vivência carcerária; Percepção do criminoso passional; Possibilidade de evitar o crime; Projetos de vida. Ao longo da coleta de dados, cada um dos entrevistados relatou o modo como ocorreu o delito que praticou. A ameaça da presença de um rival suscitou o ciúme, a intolerância, o ódio, o desespero, o sentimento de estar sem saída e o ato criminoso. Verificamos, neste estudo, que o passional não tolera o lugar de traído e, 
narcisicamente, consuma o crime para evitar a morte do seu eu. Tal como Narciso, ele toma a si mesmo como objeto de amor, amando-se por meio do outro (Kaufmann, 1996). Ele deseja a posse do objeto à sua imagem, portanto. Neste sentido, o homicida passional é um narcisista que elege a si próprio, em preferência a outros, como objeto de amor (Eluf, 2003). Ele não possui autocrítica e exige ser admirado e exaltado por qualidades que não possui. Por isso mesmo, ele se sente desprezado, morto e destruído, num quadro de profundo sofrimento em decorrência da traição. Sem ter meios para ressignificar a paixão, acaba por realizar atos criminosos que envolvem violência psicológica, lesão corporal, homicídio ou tentativa de homicídio contra a mulher amada, na fase de gestação ou não, quando o relacionamento está em vias de rompimento ou já acabado. Há casos em que a violência se dirige aos seus rivais e se estende aos filhos em tenra idade ou às pessoas mais próximas.

De acordo com os dados coletados, Amor e ódio estão no âmago dos crimes passionais. Eles são sentimentos antagônicos, presentes na vida psíquica humana e em constante atividade nos relacionamentos amorosos. Um dos entrevistados informou que sentia amor e paixão pela companheira que matou. A maioria dos entrevistados caracterizou os seus relacionamentos amorosos entre bom e maravilhoso, tanto que eles contaram que, antes do crime, "imaginavam que as suas companheiras eram gente boa, leal". Narraram que costumavam dialogar entre si e que o amor deles era recíproco. Verificamos que, por um lado, eles informaram que o relacionamento afetivo era "maravilhoso" e, por outro, no momento do homicídio, ele era puro "ódio, fora de sentido". Percebe-se que, mesmo num clima amoroso, o amor e o ódio se manifestam e podem ser transformados em atos violentos. A morte da parceira ou do rival expressa e satisfaz o ódio e a cólera (Ferreira, 2002). Sem encontrar outra saída, a vivência da traição evoca esses afetos e desencadeia o crime.

Ao relatarem os seus sentimentos no momento do crime, os entrevistados afirmaram que se sentiram desesperados, cegos, muito lesados e humilhados. Um deles contou que, na hora, ficou sem saber o que fazer, e afirmou que a loucura é que faz a pessoa matar: "o ódio, fora do sentido, é como se entrasse um demônio". Ele relatou que se passaram muitas coisas em sua cabeça, mas que ele não tinha a intenção de cometer o crime. Acrescentou que, na hora, o seu medo de perder a vida se transformou em vontade de sobreviver. Tal perspectiva se coaduna com a ideia segundo a qual, prazerosa ou dolorosa, entusiasta ou melancólica, extática ou colérica, toda paixão é desejo posto em tensão e emoções intensificadas (Kaufmann, 1996).

Com tudo isso, a maioria dos entrevistados diferenciou o amor da paixão, apesar de alguns terem informado que "é tudo igual". Os internos consideraram o amor como profundo, eterno, puro, sério, e revelaram que quem ama trata bem a mulher, faz tudo por ela e não a mata. Ao mesmo tempo, visualizaram a paixão como doentia, passageira, descontrolada, triste e finita. Essa ideia concorda com a de Cardoso (1987), para quem a paixão é uma pulsão desmedida, que vive em busca do objeto do seu desejo e o aprecia mais do que a própria vida. Assim, os maiores atos se realizam, justamente, em meio a um total excesso de amor.

No que diz respeito ao Ciúme e à rivalidade num envolvimento amoroso, vimos que estes tanto podem ocorrer após uma separação recente ou em relação a um amor do passado, a um amor que pode acabar ou, ainda, em relação a um relacionamento amoroso de pouco tempo, como o amor de carnaval, citado numa das entrevistas, ou mesmo uma união de média ou longa duração, como o relacionamento de um dos entrevistados, que durou 14 anos. As vítimas dos participantes desta pesquisa foram a namorada, a exnamorada, a mulher, a companheira grávida, o amante da namorada, o ex-namorado da namorada, o homem que foi defender a ex-mulher quando o interno corria atrás dela com uma faca, a ex-namorada grávida e noiva de outro, o homem que se encontrava junto da ex-mulher, o pretendente, o companheiro da amante, as crianças de 2 anos e de 8 meses, irmãs. O período que se segue à separação, à ameaça de separação ou à gravidez constitui os momentos em que a mulher, a família ou o rival estão mais expostos a esse tipo de crime (Chollet, 2005a).

Houve muitas controvérsias entre as entrevistas e os prontuários quanto ao tipo de relação que o interno mantinha com a vítima. Uns diziam se tratar da sua companheira e, nos prontuários, elas eram referidas como ex-companheiras. Vimos que, quando enciumados, os passionais se tornam violentos e se vingam das mulheres, companheiras, rivais e filhos, devido a uma infidelidade real ou imaginária. Durante as entrevistas, apenas um dos entrevistados informou ter ciúmes da sua mulher, enquanto todos os outros negaram este sentimento. Mesmo assim, um deles afirmou que o ciúme é "sintoma do amor", enquanto outro esclareceu que ele é a "falta de segurança do homem" e que, "em si mesmo, é a pior doença do mundo, porque traz problema" e, "quando passa do limite, fica perigoso", causando a morte. De acordo com a metade dos prontuários, os crimes foram 
motivados pelo ciúme. Ruge e Lenson (2006) acrescentam que o ciúme é uma das principais causas da violência contra crianças e da perseguição de antigos parceiros. Em relação às estatísticas da violência, os autores afirmam que as questões ligadas ao ciúme são pouco relatadas. De acordo com esses autores, o ciúme tem proporções epidêmicas, sendo a principal causa de assassinatos, violência doméstica, abuso conjugal e divórcio.

Ferreira (2002), retomando o pensamento de Daniel Lagache, ressalta que no ciúme há sempre um desequilíbrio entre o desejo e a posse, o sujeito e a realidade. A questão é que o ciumento, por não aceitar uma realidade insatisfatória, termina por recusá-la. Para esse autor, o significado do ciúme estabelece-se na luta que o sujeito trava para subjugar a realidade aos objetivos do amor. Por isso, a estrutura do estado de ciúme é sempre primitiva. Nela, a linha divisória entre a imaginação, a fantasia, a crença e a certeza é vaga e imprecisa. A autocrítica e a capacidade de controle encontram-se alteradas e o sujeito não consegue lidar com seus afetos. O ciúme se manifesta por uma conduta de dominação regressiva, que tende a negar a existência e o valor do outro, a alteridade, para afirmar a existência do seu próprio valor.

O ciúme masculino, quando manifesto, demonstra competição e extrema intolerância, levando à vivência de uma paixão ou de um amor obsessivo (Ferreira, 2002). No amor ciumento, verifica-se um enorme desejo de ser amado pelo outro, possuí-lo, conservá-lo, exigindo-se a sua presença total e contínua. $\mathrm{O}$ sujeito evita se confrontar com a falta que o amor provoca nele e deseja que o parceiro preencha este vazio. Neste estudo, os crimes passionais demonstraram que um relacionamento amoroso rompido ou sob ameaça de rompimento pode se constituir numa ameaça para o apaixonado e este pode significar a presença do outro como um estranho, como um rival. A inveja produz o sentimento de ódio ao rival. A rivalidade suscita o ciúme e o desejo de posse do objeto (Elyseu Junior, 2003). A partir daí, o passional é capturado pelo ciúme, que pode rapidamente transformar-se numa paixão impossível de ser controlada (Ruge \& Lenson, 2006).

$\mathrm{Na}$ perspectiva freudiana, a fonte primária da rivalidade é o ódio sentido em relação à intrusão da figura paterna na relação da criança com a mãe (Freud, 1910/1980; Gori, 2006). A rivalidade odiosa com o pai, na dialética edipiana, é seguida de processos de identificação com ele e de remorso por desejar-lhe o mal, que acabam por dar origem à moral e à instância do supereu. Em seu texto Totem e Tabu, Freud (1913/1980) inventa um mito para a origem da hostilidade dirigida ao pai. Ao gozar de todas as mulheres e proibir os seus filhos de fazer o mesmo, expulsando-os de sua horda, o pai primordial é assassinado por eles, que, não obstante, renunciam a este gozo, devido ao remorso produzido por este ato. Tal processo origina a Lei da interdição do incesto. Ao longo dos tratamentos dos neuróticos, Freud descobre que a rivalidade odiosa com a figura parental do mesmo sexo constitui uma das molas principais do que ele chamou de complexo de Édipo.

Em seu seminário 20, Lacan (1985) nomeia esse ódio invejoso de "gozinveja" e exemplifica isto com uma cena descrita por Santo Agostinho, na qual uma criança bem pequena é dominada pela inveja de um irmão menor, quando este mama ao seio de sua mãe (Gori, 2006). A rivalidade fraterna, estendida posteriormente a outros homens, tem como seu protótipo essa cena infantil. De acordo com Lacan (1985), numa situação desse tipo, o sujeito se percebe despojado do objeto de seu desejo. A imagem odiada reativa assim a dor da frustração primordial de separação da criança de sua mãe.

No que diz respeito à Intolerância à traição, verificamos que esta surgiu, muitas vezes, sob a forma de violência, quando parceiros amorosos não toleraram a frustração e a angústia de uma traição. Movidos por sentimentos ambíguos suscitados pela traição, a intolerância se manifesta em seus matizes. O ódio reprimido, o desejo de vingança e a intolerância que leva o agente à prática desse tipo de crime configuram uma agressividade que corrói, mina, desagrega e conduz à morte. Entre os entrevistados, a intolerância à traição emergiu mesmo depois de rompido um relacionamento, depois de longo tempo ou não. Ferreira (2002) esclarece que, do ponto de vista da gênese do pensamento criminoso, o ciumento vive um sentimento de perda e o crime passional se torna, para ele, um ato de justiça. A frustração produzida pela experiência da traição leva a intolerância ao limite extremo e a intervenção da vontade sobre o ato criminoso passa a ser mínima. Desenvolve-se uma violência estranha e automática, que arrasta o sujeito para uma perturbação motora. A ação, uma vez posta em marcha, desenrola-se espontaneamente com toda a precisão e energia necessárias ao seu objetivo. Alguns entrevistados informaram que "Não há saída para não cometer o crime, pois, no momento de desespero, o ódio transpassa a mente", a não ser que fosse uma pessoa controlada e de "mente forte". Nessa circunstância, o indivíduo passa a acreditar que ele é uma vítima inocente, e isso torna o ato de matar cada vez mais legítimo e justo para ele. A intolerância e o fanatismo 
revelam, portanto, um infantilismo narcísico e sua crueldade mais primária: se o julgo mau, elimino-o, junto com seus vizinhos (Souza, 2005).

Em relação à categoria Planejamento versus impulsividade, todos os entrevistados informaram que o delito cometido não foi planejado, mas cometido por impulso. Além disso, um deles revelou que todos os seus colegas presos que passaram por essa experiência disseram que, se pensassem antes, não teriam cometido o crime. Mesmo que esses infratores passionais estejam cumprindo pena, ainda assim é preciso associar a ela meios que lhes possibilitem demonstrar a sua capacidade humana para se apresentar, representar e significar a si e ao mundo (Barros, 2000). Talvez tais atividades possam funcionar como estratégia preventiva contra a intolerância ou mesmo contra a reincidência criminal. Os entrevistados 3, 4 e 12 mataram a vítima por impulso, sem sequer perceberem, no momento, o que estavam fazendo. Por esse aspecto, quase todos os entrevistados responderam que a sociedade não tem influência sobre o crime passional, pois a pessoa comete o delito de acordo com o seu "caráter".

A violência é, assim, uma reação à frustração (Bezerra Júnior, 2005). Para Lacan (2005), a passagem ao ato violento é consequência de um afeto intenso em confronto, que não encontrou uma saída para descarregar o seu excesso de energia psíquica. Tal estado gera uma tensão interna, um mal-estar intenso que impulsiona ao movimento. A passagem ao ato, então, se dá como uma tentativa de saída desse lugar. No momento do crime, é como se o indivíduo estivesse cego, como se houvesse tido um lapso mental: tudo acontece muito rapidamente e ele fica tonto (Coelho, 1999). Lacan (2005) ressalta que um fantasma de suicídio deve ser sempre considerado numa passagem ao ato, já que o sujeito deixa de existir nesse instante. Ações desse tipo apresentam um caráter impulsivo, que toma, muitas vezes, uma forma autoagressiva ou heteroagressiva. Essas reações estão ligadas à Pulsão de Morte e a grande maioria das vítimas falece. Para consumar o crime os entrevistados utilizaram facas, facões, espingardas, revólveres, pedaços de pau e até as suas próprias mãos. Segundo Kaufmann (1996), nesses casos a alteridade é vivenciada como insuportável, de modo que só é possível reencontrar o outro na violência.

No que diz respeito à vivência carcerária, durante as entrevistas os internos revelaram que a convivência com outros presos era "legal, tranquila, boa, em paz", que tentavam fazer o melhor possível, respeitando os demais. Quase todos os entrevistados recebiam visitas da mãe, dos filhos, da esposa, enquanto outros as recebiam de vez em quando e um deles preferia que a família não viesse visitá-lo, sob a alegação de que ele havia cometido o delito e a família não devia passar por este "constrangimento $d a$ cadeia" e por esta humilhação. Por isso, era ele quem a visitava. Outro interno ainda pedia que os visitantes não fossem vê-lo por causa das despesas, argumentando que ele saía muito da penitenciária e já ia começar a trabalhar. Muitos participantes deste estudo desenvolviam alguma atividade no presídio, como limpar o jardim, fazer artesanato, "malhar", ler, fazer faxina, trabalhar como pastor, como soldador, jogar bola e estudar. A maioria deles afirmou ter bom apetite, ao contrário de alguns, e a metade revelou que dormia bem. No entanto, alguns relataram que na cadeia não se dorme, pois se vive assustado. Quando se começa a pensar nos filhos é que vem o cochilo.

Ao serem indagados sobre como se sentiam no presídio, um deles declarou: "Vida ruim, preso não tem vida boa, é coagido". Outro respondeu que o tratamento é bom, mas que se sente preso, pagando a pena. Outros ainda afirmaram que no momento estavam em situação melhor, porque estavam trabalhando, e que antes a vida era estressante. Alguns responderam que o preso é privado de todas as coisas; que nem é possível falar; que ficar preso é péssimo; que "preso só fica esperando o dia"; que quando ele recebe visita sente-se constrangido, abalado e pede perdão; que pensa nos filhos para criar lá fora; que se sente triste, angustiado e com saudade da família. Um dos presos revelou que, depois que passa pelo sistema penitenciário, o indivíduo se torna diferente, pelo fato de a prisão ser uma escola. Ele questionou: "Como uma pessoa passa por aqui e volta?". A maneira com que um preso vivencia a punição na prisão pode ser transformada em estímulos para ele se posicionar como um sujeito social ou para cometer novos crimes. Considerar os modos pelos quais pode se dar a vivência carcerária constitui um campo fértil para pensar novas atitudes que beneficiem essa população.

Erwing Goffman e Donald Clemmer são autores de referência no que diz respeito à questão da vivência em instituições prisionais. Para Goffman (1999), a entrada de pessoas em uma instituição total, como a prisão, que abriga indivíduos em situação semelhante, separados da sociedade mais ampla por considerável período de tempo, numa vida fechada e formalmente administrada, desencadeia um processo de mortificação do eu. Esse processo é marcado por uma série de rituais, de humilhações, de degradação e profanação do eu, à qual o preso tem que se submeter.

De acordo com Goffman (1999), a impossibilidade de escapar à mortificação do eu se deve às condições 
específicas dessa vivência, que são comuns a todos os internos. O ponto principal dela é a perda do poder de decisão sobre as ações corriqueiras, já que toda a sequência de atividades na prisão é imposta e deve obedecer a um tempo determinado. Isso modifica o significado estrutural de todas as atividades diárias. A perda da liberdade é sentida quando o preso é obrigado a ter o lazer, o trabalho e o sono no mesmo local e sob a mesma autoridade, de modo que não há mais a separação destas três esferas da vida. Além disso, não há vida reservada. Cada atividade diária deve ser "realizada em companhia de um grupo relativamente grande de outras pessoas, todas elas tratadas da mesma forma e obrigadas a fazer as mesmas coisas em conjunto" (Goffman, 1999, p.18) e em horários estabelecidos pela administração da instituição. É importante pensar sobre essa questão, já que, ao invés de ser possibilitado ao sentenciado adquirir recursos para o seu convívio social, durante a sua permanência nas instituições prisionais o que ele absorve é uma nova forma de convivência, específica à comunidade que vive atrás das grades.

De acordo com a Teoria da Prisionização de Clemmer, o indivíduo, ao ser preso, passa à condição de um ser institucional, devendo adaptar-se ao tipo de vida no cárcere, apesar das violências contra a sua dignidade (Himelfarb, 2005). Até inconscientemente ele vai assimilando o modus vivendi, os hábitos, costumes e as imposições carcerárias. Isso acontece porque o indivíduo passa a ser uma figura anônima, subordinada a uma instituição. Ele aprende os graus de autoridade dos vários funcionários; adquire as gírias da cadeia; aprende ou aperfeiçoa truques para tirar vantagens ou adquirir determinados benefícios, como comida; desconfia de todos; olha com rancor os agentes penitenciários e até os companheiros; adquire comportamento sexual diverso do que possuía quando em liberdade, entre outros comportamentos e fatos (Santos, 2003); ou seja, esse indivíduo adquire um modo de vida condizente com as normas da comunidade na qual ele se encontra imerso. Apesar de nem todos estarem sujeitos a essas transformações, é inevitável que essa influência se dê em algum grau, como foi verificado com as pessoas entrevistadas.

Quanto à Percepção do criminoso passional, os participantes da pesquisa revelaram que ele é visto pelos demais como burro, fraco, anormal, que não tem consciência de espírito, é ignorante e tem mente confusa: "É burrice, somos companheiros, não é dono, só Deus tira a vida", "isto é fraqueza", "ela não é dele, o ser humano não é um objeto", "um louco, doente", "não é homem, não se mata mulher por besteira, ciúme", "ele não tem a mente normal", "é covardia". No entanto, uns expressaram que "são partes iguais, ela também não ia gostar dele com outra mulher". Os internos revelaram que um homem que mata a sua mulher está possuído por algo: "o inimigo". Está despreparado, lembrou-se da paixão e se sentiu perseguido. Se ele soubesse das consequências disso, não teria cometido o delito.

A maioria dos entrevistados não se acham diferentes das pessoas que passaram por uma experiência de traição e não cometeram o crime, justificando não conhecerem quem tenha passado por isto e não tenha praticado o delito: "não faz na hora, mas depois faz"; "não, a gente não é inferior a ninguém"; "se ele passasse pelo que ele passou, cometeria o delito". Alguns presos informaram que a única diferença entre eles e os demais que não cometeram o delito é a força para resistir ao que viram, a possibilidade de pensar melhor e buscar outro caminho. Os internos afirmaram que o crime não compensa e que pensaram em aconselhar as pessoas a não cometê-lo. As suas percepções demonstram, após o homicídio, uma consciência do crime, de suas consequências e da transformação que uma passagem ao ato produz no indivíduo. Em qualquer estrutura psíquica a passagem ao ato pode operar uma transformação, já que, quando o sujeito faz uma passagem ao ato, algo nele se perde e ele se modifica (Coelho, 1999).

A suposta paridade entre criminosos passionais e aqueles que não cometem este tipo de delito é questionável, uma vez que, como apontado, certas condições psicológicas precisam estar presentes para que o crime aconteça. Diferentemente das demais pessoas, o passional não tolera o lugar de traído e, narcisicamente, consuma o crime para evitar a morte do seu eu (Kaufmann, 1996). Para ele, a alteridade é insuportável, o que o faz eleger a si próprio como objeto de amor (Eluf, 2003). Capturado pela rivalidade e ciúme (Ruge \& Lenson, 2006) e impossibilitado de lidar com a frustração e a perda (Ferreira, 2002), esse indivíduo não consegue controlar os seus impulsos e acaba por efetuar uma passagem ao ato criminosa, descarregando o seu excesso de energia psíquica (Lacan, 2005).

Ainda em relação à Percepção do criminoso passional, os internos relataram as duras consequências da estigmatização: "Ninguém vai dar confiança em mim"; "Pensa que agente sai pior da prisão". Um dos entrevistados lembrou que "o índice de incidência é alto porque a sociedade não dá oportunidade", pensa que ele é um criminoso. As pessoas o abandonam devido ao crime: "Olha lá o assassino frio, cuidado com ele, matou um mata dez". As pessoas os veem como ruins e cruéis. De acordo com Saliba e Saliba (2006), a sanção penal é estigmatizante e traz graves consequências ao ser humano, desencadeando um processo de exclusão e morte social. $\mathrm{O}$ indivíduo é atingido pelos impactos 
sociais da prisão, pela violência da discriminação, de onde surge o estigma como uma construção social de natureza relacional, legitimada pelo olhar do outro. Esse outro compreende uma rede de normas, códigos e comportamentos de um grupo que circunscreve, de forma simbólica ou concreta, territórios de normalidade.

Em relação à Possibilidade de evitar o crime, a maioria dos entrevistados respondeu positivamente. Por outro lado, quando lhes foi perguntado se seria possível, no momento do desespero, uma pessoa buscar outra atitude diferente do ato criminoso para resolver o problema, alguns declararam não haver outra saída a não ser o delito. Um dos internos declarou que, se desistisse do crime, poderia ter morrido. Outros relataram não querer nem pensar nisso; que isto nunca se passa em sua mente; que não sabem se aguentariam; que amarrariam uma corda no pescoço e morreriam. Algumas expressões no discurso dos entrevistados demonstraram o risco de reincidência criminal: "Quero ver na hora"; "Se eles experimentassem o que eu vivi..."; "Não faz na hora, mas depois faz"; "que não conhece pessoa alguma que passou por isso e não praticou o crime". Já os que defenderam a posição contrária de evitação do crime afirmaram que isto só seria possível para alguém que tivesse uma "mente forte", que fosse uma pessoa muito controlada, que soubesse o que era cadeia, pois o flagrante é uma situação muito difícil que, por isto, para muitos não possibilita outra reação. A chegada de um amigo no momento de desespero, uma conversa, um apoio religioso, "meter o tapa na cara, dar murro" ou o suicídio foram ainda apontados como alternativas para o não cometimento do delito.

Alguns pesquisadores persistem em compreender a violência masculina com o intuito de vencê-la, e apontam como única saída para ela a escuta dos passionais (Chollet, 2005b). Essa escuta lhes possibilitaria dar voz à paixão que os atormenta e que pode impulsionar o indivíduo às malhas do crime. Fundamenta essa proposição a ideia segundo a qual o símbolo atesta a perda da coisa simbolizada (Cardoso, 1987). Por meio da fala o indivíduo pode tentar dar conta desse acontecimento trágico de sua vida e se interrogar sobre a sua verdade e o seu desejo (Danziato, 2007). A maioria dos entrevistados revelou que, se passasse novamente pela mesma experiência, reagiria de modo diferente, evitando o problema.

Em relação aos seus Projetos de vida, durante a entrevista os internos informaram que, antes do acontecimento do crime, viviam normalmente como cidadãos de bem, trabalhando, sem desavenças e sem problemas. Eles sonhavam em construir uma linda família com a vítima e lembraram que este foi o relacionamento mais lindo e o pior de todos os que já tiveram. Sonhavam ter sua casa, um trabalho fixo para não passar necessidade, ver os filhos criados, os netos, todos juntos, arrumar um "canto" para colocar os seus filhos. Quando saíssem da cadeia, eles pretendiam buscar uma vida melhor: terminar seus estudos, ter um bom emprego, um bom cargo, trabalhar para ganhar mais e ajudar a família. Pretendiam ainda ir para São Paulo ou Brasília, conviver felizes com a companheira, ter uma boa casa, um bom carro, uma embarcação, um veleiro, ser uma pessoa independente e ver sua mãe e sua família se sentindo bem.

Ao mesmo tempo em que os presos entrevistados apresentaram elementos configuradores de seus projetos de vida, revelaram quanto este projeto é difícil de ser realizado, devido ao processo de estigmatização sofrido com o encarceramento. Segundo Goffman,

Nos muitos casos em que a estigmatização do indivíduo está associada com sua admissão a uma instituição de custódia, como uma prisão, um sanatório ou um orfanato, a maior parte do que ele aprende sobre o seu estigma ser-lhe-á transmitida durante o prolongado contato íntimo com aqueles que irão transformar-se em seus companheiros de infortúnio (Goffman, 1988, p.46).

Na perspectiva desse autor, o problema central da situação de vida do indivíduo estigmatizado é a sua aceitação, ou seja, a discrepância entre a identidade social a ele atribuída e a sua identidade real, com suas infinitas possibilidades. Ele se encontra, desta forma, impossibilitado de uma aceitação social plena, pois o estigma a ele atribuído organiza a forma como as pessoas se relacionam e se comunicam com ele. Vemos, assim, que a comunidade se relaciona antes com o estigma do que com o sujeito. Em decorrência disso, o indivíduo encontra dificuldades na ressocialização após a prisão, já que sua posição no mundo externo não é mais a mesma após a vivência carcerária (Goffman, 1999). Isso dificulta muito a concretização de seu projeto de vida após a saída da prisão.

\section{CONSIDERAÇÕES FINAIS}

Entre os aspectos principais deste estudo, verificamos que os crimes passionais são motivados pela impossibilidade dos indivíduos de lidar com a situação de traição, real ou imaginária. Diante do ciúme, do ódio e da rivalidade, a resposta impulsiva que surge é o ato de violência, que culmina, muitas vezes, na morte da vítima. Ainda que o indivíduo posteriormente se arrependa, ele é 
condenado judicialmente e colocado numa unidade prisional, juntamente com outros indivíduos que cometeram delitos diferentes do seu. $\mathrm{O}$ sofrimento desencadeado por essa experiência de privação da liberdade, assim como pela estigmatização dela decorrente e pelas condições precárias do estabelecimento penal, produz uma reflexão sobre o projeto de vida e o desejo de prevenir um novo ato desta natureza. A oferta de assistência psicológica e a discussão em torno de alguns valores sociais ligados à cultura do machismo podem, então, contribuir para um reposicionamento dos indivíduos diante da situação de traição.

\section{REFERÊNCIAS}

Aquino, R. A. (2006). Crime: a violência cega dos maridos. Época, 444, 100-101.

Bardin, L. (1977). Análise de conteúdo. Lisboa: Edições 70.

Barros, M. N. F. (2000). Violência contra a mulher: as marcas do ressentimento. PSI - Psicol. Soc. Instit., 2(2), 129-148.

Beraldo Júnior, B. R. (2004). Legítima defesa da honra como causa excludente de antijuridicidade. Jus Navigandi, 367. Recuperado $\begin{array}{llllll}\text { em } & 30 & \text { de } & \text { abril de } & 2007 & \mathrm{em}\end{array}$ http://jus2.uol.com.br/doutrina/texto.asp?id=5418

Bezerra Júnior, B. (2005). A violência como degradação do poder e da agressividade. Em Sociedade Brasileira de Psicanálise de Porto Alegre. Pensando a violência com Freud (pp.111-122). Porto Alegre: SBP de PA.

Bibeau, G \& Corin, E. (1995). From submission to the text to interpretative violence. In G. Bibeau, E. Corin (editors). Beyond textuality. Ascetism and violence in anthropological interpretation. Approaches to semiotics series (pp. 3-54). Berlin: Mouton de Gruyter.

Cardoso, S. (1987). Os sentidos da paixão. São Paulo: Companhia de Letras.

Chollet, M. (2005a). Machismo sem fronteiras. (R. S. Campos, Trad.). Le Monde Diplomatique. Recuperado em 27 de abril de 2007 em http://diplo.uol.com.br/2005-05,a1101

Chollet, M. (2005b). Uma "Moléstia social". (R. S. Campos, Trad.). Le Monde Diplomatique. Recuperado em 19 de abril de $2007 \mathrm{em}$ http://diplo.uol.com.br/2005-05,a1100

Coelho, M.T.A.D. (1999). Um crime de morte e de corte. Em Atas, volume II, Reunião Lacanoamericana de Psicanálise da Bahia (pp. 808-811). Salvador: ELBA.

Danziato, L. (2007). Intolerância à dor. VIVA - Diário do Nordeste. Manias Normais. Fortaleza/Ceará, 29/4/2007. Recuperado em 21 de maio de 2007 em www.verdes mares.com.br

Eluf, L. N. (2003). A paixão no banco dos réus: casos passionais célebres de Pontes Visgueiro a Pimenta Neves. São Paulo: Saraiva.

Elyseu Júnior, S. (2003). Complexo fraternal: a fonte do ciúme e da inveja. Psicol. teor. prat., 2(5), 55-66.
Ferreira, I. (2002). Flechas errantes: um ensaio sobre o ciúme. Recuperado em 09 de abril de 2007 em www.stormmagazine.com/arquivo/Artigos_Fev_Mar/Sociedade/s_mar2002_ 1a.htm

Freud, S. (1910/1980). Um tipo especial de escolha de objeto feita pelos homens (contribuições à psicologia do amor I). Em Edição Standard Brasileira das Obras Psicológicas Completas de Sigmund Freud. Rio de Janeiro: Imago.

Freud, S. (1913/1980). Totem e tabu. Em Edição Standard Brasileira das Obras Psicológicas Completas de Sigmund Freud. Rio de Janeiro: Imago.

Goffman, E. (1988). Estigma: notas sobre a manipulação da identidade deteriorada. $4^{\mathrm{a}}$ ed. Rio de Janeiro, Zahar.

Goffman, E. (1999). Manicômios, prisões e conventos. 6. ed. São Paulo: Perspectiva.

Gori, R. (2006). O realismo do ódio. Psicol. clin., Rio de Janeiro, $18(2)$.

Himelfarb, I. T. (2005). Cooperativismo Social e a produção de liberdade nos egressos do sistema penal. O estudo de caso de duas cooperativas sociais. Dissertação de mestrado não publicada, PPG de Ciências Sociais Aplicadas em Políticas e Práticas Sociais, Unisinos, São Leopoldo.

Kaufmann, P. (1996). Dicionário enciclopédico de psicanálise: o legado de Freud e Lacan. (V. Ribeiro e M. L. X. A. Borges, Trad.). Rio de Janeiro: Jorge Zahar.

Lacan, J. (1985). O Seminário, livro 20: mais, ainda. (M.D. Magno, Trad.). Rio de Janeiro: Jorge Zahar.

Lacan, J. (2005). O Seminário, livro 10: a angústia. (V. Ribeiro, Trad.). Rio de Janeiro: Jorge Zahar.

Marcondes Filho, C. (2001). Violência fundadora e violência reativa na cultura brasileira. São Paulo Perspectiva, 15(2): 20-27.

Minayo, M. C. S. (2004). Pesquisa social: teoria, método e criatividade. Petrópolis: Vozes.

Osório, L. C. (2002). Casais e família: uma visão contemporânea. Porto Alegre: ArtMed.

Ruge, K. C. \& Lenson, B. (2006). A síndrome de Otelo: vencendo o ciúme, a traição e a raiva em seu relacionamento. (C. G. Duarte,Trad.). Rio de Janeiro: Best Seller.

Saliba, M. G., Saliba, M. G. (2006). Violência doméstica e familiar. Crime e castigo. Jus Navigandi, 1146. Recuperado em 11 de abril de $2007 \mathrm{em}$ http://jus2.uol.com.br/doutrina/texto.asp?id=8824

Santos, E. T. (2003). O Fenômeno da Prisonização: uma experiência no Complexo Médico-Penal do Paraná. Monografia de especialização não publicada, Programa de Pós-Graduação em "Modalidades de Tratamento Penal e Gestão Prisional". Universidade Federal do Paraná, Curitiba.

Souza, L. R. (2005). Violência. São Paulo: Casa do Psicólogo.

Recebido em 17/06/2008 Aceito em 21/10/2009

Endereço para correspondência : Rosilene Almeida Santiago. Rua Nossa Senhora de Guadalupe, 17, Acupe de Brotas, CEP 40290-250, Salvador-BA, Brasil. E-mail: almeida.rosilene@yahoo.com.br 
